\title{
Effect of moisture content of cohesive subgrade soil
}

\author{
Adnan Zainorabidin ${ }^{1}$ and Dian Hastari Agustina ${ }^{1, *}$ \\ ${ }^{1}$ Faculty of Civil and Environmental Engineering, Universiti Tun Hussein Onn Malaysia, 86400 Parit \\ Raja, Johor, Malaysia
}

\begin{abstract}
A good subgrade for road pavement is required to support the traffic load that passes through. The characteristics of the subgrade is determined by the stress-strain behaviour that is expressed as a resilient modulus. The performance of the pavement is affected by characteristics of the subgrade. Characteristics of clay soil generally have a low of bearing capacity, especially to support the load induced by the wheel load of vehicles. Clay soil is very sensitive to changes of temperature and moisture content. The changes of moisture content cause the changes on the subgrade's resilient modulus value. This paper studies the resilient modulus of the subgrade of clay soil by laboratory testing. To investigate the effect of moisture content, this testing is done on a dry side, OMC condition and wet side. The result shows the difference of the resilient modulus characteristic and deformation that is influenced by the moisture content.
\end{abstract}

\section{Introduction}

Subgrade is a very important layer in pavement design. Subgrade soil that is designed to support the pavement structure can be provided by natural soil, embankment soil and cut or fill soil $[1,2]$. The characteristics of a subgrade material must have the engineering requirements of properties such as stiffness and strength. Resilient modulus is the important value to characterize subgrade soil for pavement design. Therefore, road pavements require a subgrade that is able to withstand the load received because pavements should not fail during their design life.

Soil is a very variable material, it's related with soil texture, moisture content, density and strength. Moisture content has a significant influence on the resilient modulus for fine grained soil. In a few decades, several researchers have studied the influences of moisture content on subgrade resilient modulus [3-8]. Moisture content of subgrade soils is one of the important variables to predict the resilient modulus $\left(\mathrm{M}_{\mathrm{R}}\right)$ value [9]. The objective of this study is to show the effect of various moisture contents on the resilient modulus of cohesive subgrade soil.

Cyclic repeated loads are used to simulate traffic loading, subgrade materials are characterized by the increase of cyclic loading that follow with the increase of permanent

\footnotetext{
* Corresponding author: dian_rajendra@yahoo.com
} 
strain. After a few hundred cyclic loads, the deformations will be stabilized and it is called 'resilient modulus' [1, 10, 11]. Resilient modulus is used to measure the stiffness of pavement materials. The resilient modulus is a stress-strain relationship and defined as the ratio of axial deviator stress to recoverable resilient (elastic) strain in repeated loading. The resilient modulus $\left(\mathrm{M}_{\mathrm{R}}\right)$ was calculated from the load and deformation using the following equation:

$$
M_{R}=\stackrel{\sigma_{d}}{e_{r}}
$$

where $\quad \mathrm{M}_{R}=$ resilient modulus

$$
\begin{aligned}
\sigma_{d} & =\text { axial deviator stress } \\
\varepsilon_{\mathrm{r}} & =\text { recoverable (resilient) strain. }
\end{aligned}
$$

The amount of strain depends on the level of stress applied. Deformation shows the critical design variable of strain. Strain is defined as the ratio of the change in length to the original length in the same direction. Strain can be calculated for any direction, for example vertical, horizontal, and longitudinal [12]. The response of the deformation of materials due to repeated load, namely traffic type loading is defined by the resilient response which is characterized as the pavement's long-term performance. Fig. 1 shows an illustration of resilient and permanent strain for one cycle of cyclic load application $[12,13]$.

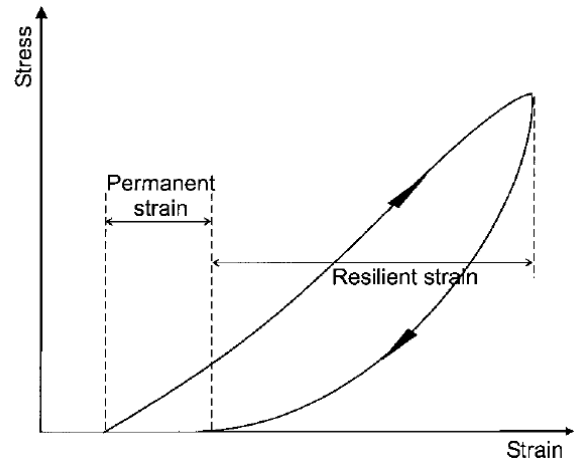

Fig. 1. One cycle of cyclic load application.

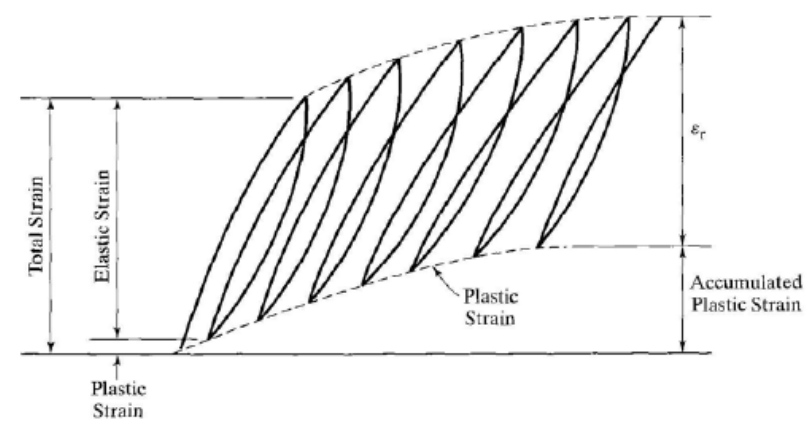

Fig. 2. Strains under repeated load.

Figure 2 above, shows the strain of a specimen under repeated load test. In the earlier stage of load applications, there is a considerable permanent deformation as indicated by the plastic strain. As the number of repetitions increase, the plastic strain due to each load repetition decreases. Strain is almost all recoverable after 100 to 200 repetitions of loads [14]. 
Soil stiffness is characterized by the loading conditions and the number of repetitions are precisely assumed. Some factors affect the resilient modulus like water content and dry density, stress level, compaction, thixotropy, suction and loading frequency $[12,15]$. Typically, subgrade materials are identified by their resistance to deformation under load, which can be a measure of the strength of stiffness.

\section{Materials and methods}

\subsection{Materials}

The disturbed soil used in this study is Batu Pahat clay that is taken using backhoe at a depth of 2 meters from the Research Centre of Soft Soil Universiti Tun Hussein Onn Malaysia (RECESS, UTHM). Table 1. Below, the geotechnical properties of the clay soil is shown.

Table 1. Geotechnical properties of Batu Pahat clay soil.

\begin{tabular}{|l|c|}
\hline \multicolumn{1}{|c|}{ Soil Characteristic } & value \\
\hline Natural water content (\%) & 92.88 \\
\hline Liquid limit (\%) & 55.54 \\
\hline Plastic limit (\%) & 24.58 \\
\hline Plastic index (\%) & 30.96 \\
\hline Specific gravity & 2.61 \\
\hline Particles: & 0 \\
Gravel fraction, percent retained above sieve 4,75 mm (\%) & 5.87 \\
Coarse fraction, percent retained above sieve 0.075 mm (\%) & 94.13 \\
\hline Fine fraction, percent passing sieve 0.075 mm (\%) & $\mathrm{CH} / \mathrm{A}-7-6$ \\
\hline USCS / AASHTO Classification & $28 \%$ \\
\hline Optimum water content (OMC) (\%) & 1.85 \\
\hline Maximum Dry Density (MDD) gr/cm ${ }^{3}$ & \\
\hline
\end{tabular}

\subsection{Methods}

A fundamental geotechnical test was conducted in this study such as the Atterberg limit, sieve analysis, specific gravity and standard proctor test. A standard proctor test is used to determine the maximum dry density (MDD) and optimum moisture content (OMC) based on guidelines of BS (1993) part 4.

The resilient modulus test was conducted on fine materials as per the standard AASHTO T.307 using the machine Load Trac II (Geocomp). According to the standard, the soil was classified as type II (fine grained). The soil sample was prepared with a $50 \mathrm{~mm}$ diameter and height of $100 \mathrm{~mm}$. The resilient modulus test is conducted with 15 sequences that consist of two phases as shown in table 2. In the first phase, the test began with a conditioning phase (sequence 0 ) which consists of applying 500-1000 repetitions of load. In the second phase, the specimen is submitted to cycle loading that consists of applying 100 repetitions of load. The cyclic axial stress using a haversine-shape consists of a 0.1 second load pulse followed by a 0.9 second rest period. 
Table 2. Testing sequence for subgrade soil (Type II). (AASHTO T-370).

\begin{tabular}{|c|c|c|c|c|c|c|c|c|c|}
\hline \multirow[t]{2}{*}{$\begin{array}{c}\text { Sequence } \\
\text { No. }\end{array}$} & \multicolumn{2}{|c|}{$\begin{array}{c}\text { Confining } \\
\text { Pressure }\left(\mathbf{S}_{3}\right) \\
\end{array}$} & \multicolumn{2}{|c|}{$\begin{array}{c}\text { Max.Axial } \\
\text { Stress }\left(\mathbf{S}_{\max }\right)\end{array}$} & \multicolumn{2}{|c|}{$\begin{array}{c}\text { Cyclic Stress } \\
\left(\mathbf{S}_{\text {cyclic }}\right)\end{array}$} & \multicolumn{2}{|c|}{$\begin{array}{c}\text { Constant Stress } \\
\left(0.1 \mathrm{~S}_{\mathrm{max}}\right)\end{array}$} & \multirow{2}{*}{$\begin{array}{c}\text { No. of } \\
\text { Load } \\
\text { Application }\end{array}$} \\
\hline & $\mathbf{k P a}$ & psi & $\mathbf{k P a}$ & psi & $\mathbf{k P a}$ & psi & $\mathbf{k P a}$ & psi & \\
\hline 0 & 41.4 & 6 & 27.6 & 4 & 24.8 & 3.6 & 2.8 & 0.4 & $500-1000$ \\
\hline 1 & 41.4 & 6 & 13.8 & 2 & 12.4 & 1.8 & 1.4 & 0.2 & 100 \\
\hline 2 & 41.4 & 6 & 27.6 & 4 & 24.8 & 3.6 & 2.8 & 0.4 & 100 \\
\hline 3 & 41.4 & 6 & 41.4 & 6 & 37.3 & 5.4 & 4.1 & 0.6 & 100 \\
\hline 4 & 41.4 & 6 & 55.2 & 8 & 49.7 & 7.2 & 5.5 & 0.8 & 100 \\
\hline 5 & 41.4 & 6 & 68.9 & 10 & 62 & 9.0 & 6.9 & 1.0 & 100 \\
\hline 6 & 27.6 & 4 & 13.8 & 2 & 12.4 & 1.8 & 1.4 & 0.2 & 100 \\
\hline 7 & 27.6 & 4 & 27.6 & 4 & 24.8 & 3.6 & 2.8 & 0.4 & 100 \\
\hline 8 & 27.6 & 4 & 41.4 & 6 & 37.3 & 5.4 & 4.1 & 0.6 & 100 \\
\hline 9 & 27.6 & 4 & 55.2 & 8 & 49.7 & 7.2 & 5.5 & 0.8 & 100 \\
\hline 10 & 27.6 & 4 & 68.9 & 10 & 62 & 9.0 & 6.9 & 1.0 & 100 \\
\hline 11 & 13.8 & 2 & 13.8 & 2 & 12.4 & 1.8 & 1.4 & 0.2 & 100 \\
\hline 12 & 13.8 & 2 & 27.6 & 4 & 24.8 & 3.6 & 2.8 & 0.4 & 100 \\
\hline 13 & 13.8 & 2 & 41.4 & 6 & 37.3 & 5.4 & 4.1 & 0.6 & 100 \\
\hline 14 & 13.8 & 2 & 55.2 & 8 & 49.7 & 7.2 & 5.5 & 0.8 & 100 \\
\hline 15 & 13.8 & 2 & 68.9 & 10 & 62 & 9.0 & 6.9 & 1.0 & 100 \\
\hline
\end{tabular}

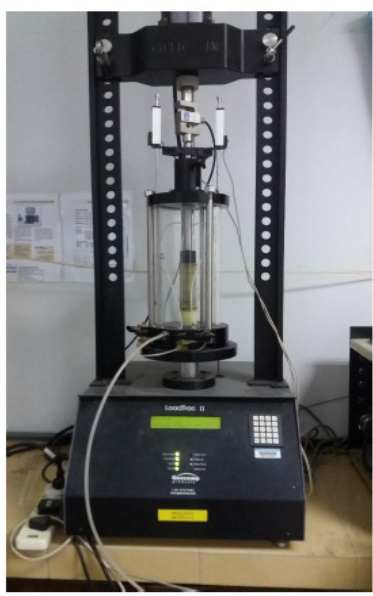

(a)

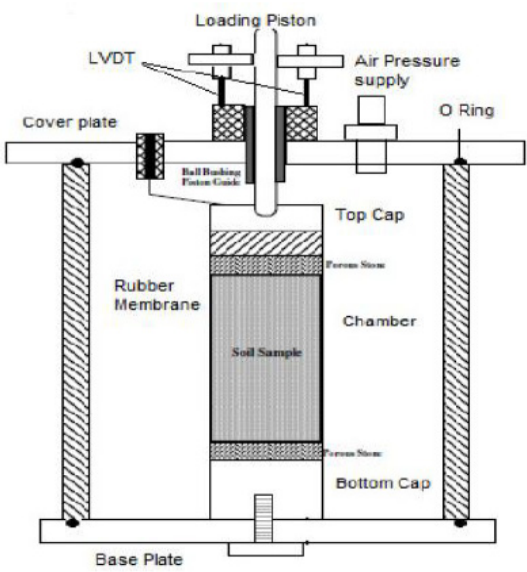

(b)

Fig. 3. (a) GEOCOMP fully automated resilient modulus machine (b) schematic diagram of resilient modulus [16].

\section{Result and discussions}

Each sample has been compacted at five different moisture contents as can be seen below before the test of resilient modulus $\left(\mathrm{M}_{\mathrm{R}}\right)$.

Table 3. Moisture content for soil testing.

\begin{tabular}{|c|c|c|}
\hline $\begin{array}{c}\text { Target moisture } \\
\text { content (\%) }\end{array}$ & $\begin{array}{c}\text { Moisture content } \\
\text { of } \mathbf{M}_{\mathbf{R}} \text { test }(\mathbf{\%})\end{array}$ & Moisture condition \\
\hline 22.4 & 21.87 & OMC- $20 \% *(\mathrm{OMC})$ \\
\hline 25.2 & 24.65 & OMC- $10 \% *(\mathrm{OMC})$ \\
\hline 28 & 27.85 & OMC \\
\hline 30.8 & 30.23 & OMC $+10 \% *(\mathrm{OMC})$ \\
\hline 33.6 & 33.34 & OMC $+20 \% *(\mathrm{OMC})$ \\
\hline
\end{tabular}


Figure 4 presents the result of resilient modulus with various moisture contents. A total of 16 loading sequence was used for the repeated load test. The summary result shows the influence of the moisture content on the mechanical strength of soil. The highest resilient modulus $\left(\mathrm{M}_{\mathrm{R}}\right)$ value is at the OMC condition. According to the OMC-MDD curve, this can be explained when the sample is not at the optimum moisture content (OMC) point, and the dry density of soil is not at the maximum dry density (MDD) condition but at a position lower than the maximum dry density. Addition of more water soil can produce its saturation and it's very difficult to compact, also if compaction is for soil with low water content [17].

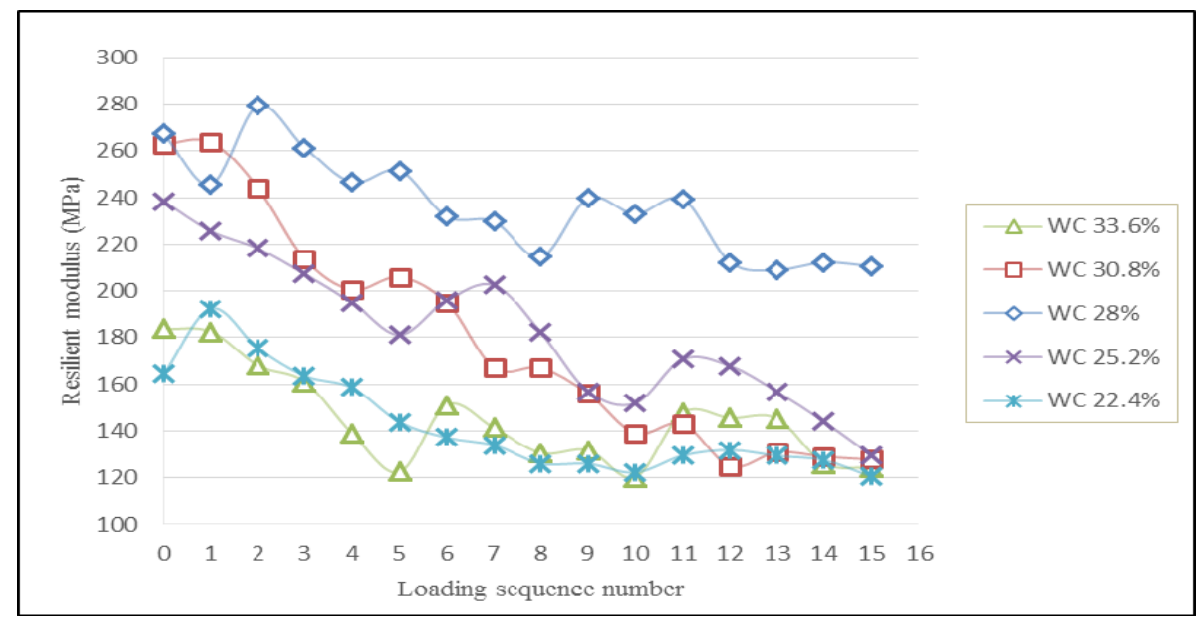

Fig. 4. Resilient modulus value of various of moisture content for each loading sequence number.

Figure 5 shows the data at constant confining pressure representing the resilient modulus at various deviator stresses. The resilient modulus $\left(\mathrm{M}_{R}\right)$ value changes when the moisture content increases or decreases from the optimum moisture content. When the water content increases by $10 \%$ of OMC $(+2.8 \%)$ and decreases by $10 \%$ of OMC $(-2.8 \%)$, the $\mathrm{M}_{\mathrm{R}}$ value respectively decreases by $24 \%$ and $22 \%$, and when the water content increases by $20 \%$ of OMC $(+5.6 \%)$ and decreases by $20 \%$ of OMC $(-5.6 \%)$, the $\mathrm{M}_{\mathrm{R}}$ value respectively decreases by $39 \%$ and $40 \%$.

Table 4. Average of resilient modulus vs confining pressure at various water content.

\begin{tabular}{|c|c|c|c|c|c|}
\hline \multirow{2}{*}{$\begin{array}{l}\text { Confining } \\
\text { Pressure } \\
\text { (kPa) }\end{array}$} & \multicolumn{5}{|c|}{ Resilient modulus $\left(\mathrm{M}_{\mathrm{R}}\right)$ value for various moisture content (MPa) } \\
\hline & $\begin{array}{c}\text { OMC-20\%OMC } \\
(22.4 \%)\end{array}$ & $\begin{array}{c}\text { OMC-10\%OMC } \\
(25.2 \%)\end{array}$ & $\begin{array}{l}\text { OMC } \\
(28 \%)\end{array}$ & $\begin{array}{c}\text { OMC+10\%OMC } \\
(30.8 \%)\end{array}$ & $\begin{array}{c}\text { OMC }+20 \% O M C \\
(33.6 \%)\end{array}$ \\
\hline 41.4 & 167 & 205 & 257 & 226 & 155 \\
\hline 27.6 & 129 & 178 & 230 & 165 & 135 \\
\hline 13.6 & 128 & 154 & 217 & 131 & 138 \\
\hline $\begin{array}{l}\text { Average } \\
\text { of } M_{R}\end{array}$ & 143 & 183 & 236 & 179 & 145 \\
\hline
\end{tabular}




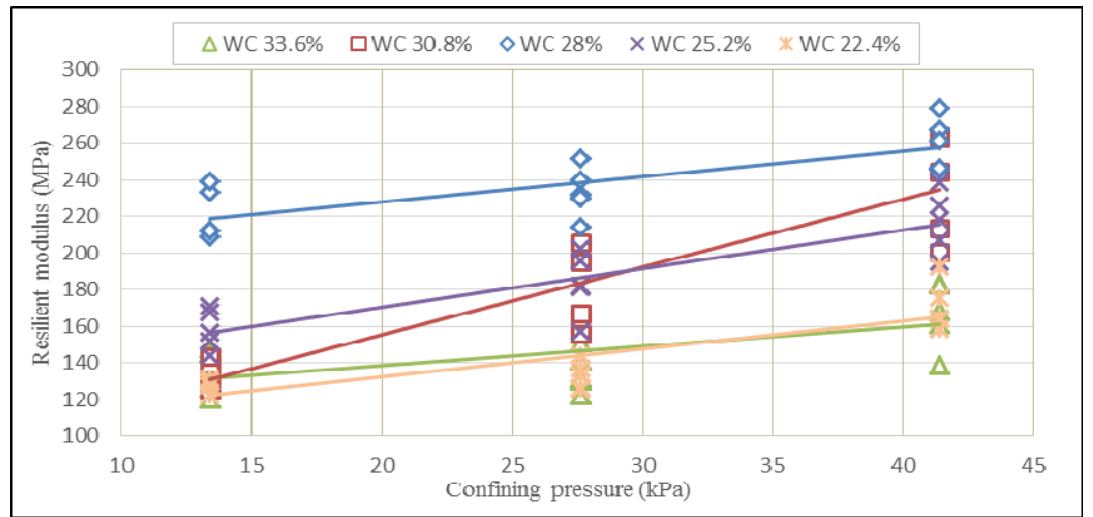

Fig. 5. Resilient modulus vs confining pressure at various water content.

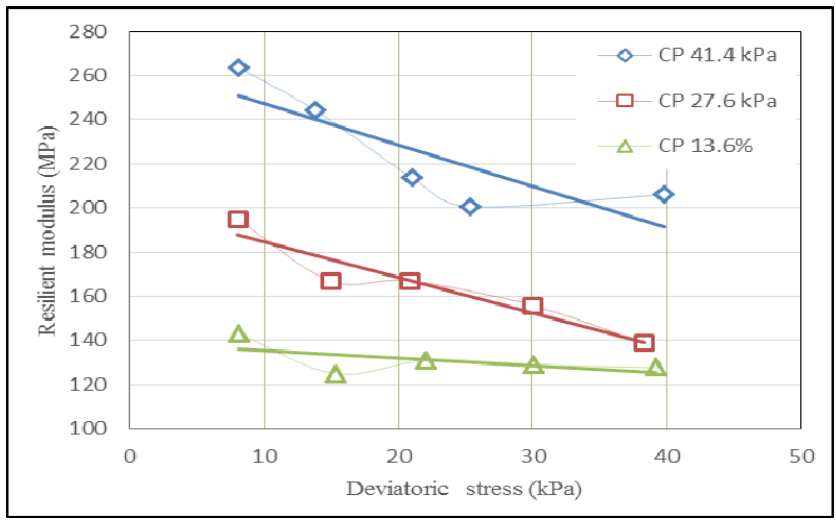

Fig. 6. Resilient modulus vs deviatoric stress for $30.8 \%$ of moisture content.

Figure 6, shows the influence of the deviator stress on the resilient modulus of cohesive subgrade showing that the decrease of the resilient modulus as the deviator stress increased at a constant confining pressure. The resilient modulus of soil is stress dependent, the confining stress and deviator stress all influence the resilient modulus value. The resilient modulus increases with the increase of confining stress and decreases slightly as the deviator stress increases [18].

\section{Conclusion}

Resilient modulus of subgrade is one of the key material properties that is required for pavement design and analysis. Cyclic repeated load that is used on the resilient modulus test is used to simulate the traffic load condition. The resilient modulus of subgrade is not strength but stiffness where a subgrade can support a high amount of load applied with very slight deformation. Moisture content has a significant effect on cohesive soil type on the dry-wet conditions, this causes the decrease of resilient modulus.

The resilient modulus increases due to an increasing moisture content until it reaches the optimum moisture content, the increase of water content next will cause a decrease on resilient modulus. Clay has a high sensitivity to moisture content variation that very significantly affects the changes of the resilient modulus $\left(M_{R}\right)$ value.

The author would like to thank the Universiti Tun Hussein Onn Malaysia (UTHM) who has funded this research project under research grant No. Vot. U.571 and also the Recess Centre for Soft Soil (RECESS-UTHM) laboratory which has supported these research activities. 


\section{References}

1. E.J. Yoder, M.W. Witczak, Principles of Pavement Design, J Wiley and Sons Inc, second edition (1975)

2. M.P. O'Reilly, S.F. Brown, Cyclic loading of Soils: from theory to design, Blackie and Sons, Ltd. London (1991)

3. B.T. Nguyen, A. Mohajerani, Resilient Modulus of Some Victorian Fine-Grained Soils at $O M C$, Wet of OMC, and Soaked Conditions, J. Aust. Geomech. Society, 49(2), 7384 (2014)

4. R. Ji, N. Siddiki, T. Nantung, D. Kim, Evaluation of Resilient Modulus of Subgrade and Base Materials in Indiana and Its Implementation in MEPDG, The Scientific World Journal, Vol.2014 (2014)

5. G. Baladi, T. Dawson, C. Sessions, Pavement Subgrade MR Design Values for Michigan's Seasonal Changes, Report No. RC-1531, Technical Report, Michigan Department of Transportation (2009)

6. M. Zaman, N. Khoury, Effect of Soil Suction and Moisture on Resilient Modulus of Subgrade Soils in Oklahoma (No. ORA 125-6662) (2007)

7. A. Maher, T. Bennert, N. Gucunski, W.J. Papp Jr., Resilient Modulus Properties of New Jersey Subgrade Soils (No. FHWA NJ 2000-01,) (2000)

8. P.R. Fleming, C. Rogers, M.W. Frost, A. Dawson, Subgrade Equilibrium Water Content and Resilient Modulus for UK Clays (1998).

9. K.P. George, Prediction of Resilient Modulus from Soil Index Properties, Final report, No. FHWA/MS-DOT-RD-04-172, Missisippi Department of Transportation (2004)

10. S. Buchanan, Resilient Modulus: What, Why, and How, Vulcan Materials Company, 8(31), 07 (2007).

11. P. Hornych, A. El Abd, Selection and evaluation of models for prediction of permanent deformations of unbound granular materials in road pavements. Work Package, 5 (2004).

12. F. Lekarp U. Isacsson, A. Dawson, State of the art. II: Permanent strain response of unbound aggregates, Journal of Transportation Engineering, 126(1), 76-83 (2000b)

13. P. Davich, J.F. Labuz, B. Guzina, B, A. Drescher, Small strain and resilient modulus testing of granular soils, Technical report, No. 2004-39, Minnesota Department of Transportation (2004)

14. Y.H. Huang, Pavement Analysis and Design, by Prentice-Hall, Inc., New Jersey (1993)

15. G.Y. Yesuf, Influence of Subsoil Conditionson the Design and Performance of Flexible Pavements, Thesis, Norwegian University of Science and Technology (2014)

16. A.J.L.M. Siang, D.C. Wijeyesekera, L.S. Mei, A. Zainorabidin, Innovative Laboratory Assessment of the Resilient Behaviour of Materials (Rigid, Elastic and Particulates), Procedia Engineering, 53, 156-166 (2013)

17. A.M.A. Guerrero, Effects of the Soil Properties on The Maximum Dry Density Obtained from The Standard Proctor Test, Thesis, Department of Civil and engineering, University of Central Florida Orlando, Florida (2004)

18. X. Kang, G.C. Kang, K.T. Chang, L. Ge, Chemically Stabilized Soft Clays for RoadBase Construction, J. of Materials in Civil Engineering, 27(7) (2014) 